\title{
Anterior segment changes following intravitreal bevacizumab injection for treatment of neovascular glaucoma
}

This article was published in the following Dove Press journal:

Clinical Ophthalmology

23 May $201 \mathrm{I}$

Number of times this article has been viewed

MI Canut ${ }^{\prime}$

A Alvarez ${ }^{2}$

J Nadal ${ }^{3}$

R Abreu ${ }^{4}$

JA Abreu

JS Pulido 6

'Glaucoma Section, ${ }^{2}$ Barraquer Ophthalmology Centre, ${ }^{3}$ Retina and Vitreous Unit, Macula Section, Institut Universitari Barraquer, Universidad Autonoma de Barcelona, Barcelona, Spain, ${ }^{4}$ Retina and Vitreous Unit, University Hospital of La Candelaria, Tenerife, ${ }^{5}$ Glaucoma Section, University Hospital of the Canary Islands, Tenerife, Spain; ${ }^{6}$ Retina and Vitreous Unit, Ophthalmology Department, Mayo Clinic, Rochester, MN, USA
Correspondence: MI Canut Jordana c/ Muntaner 314, Barcelona 0802 I, Spain Tel +34 93209531 I

Fax +34 932002469

Email mcanut@co-barraquer.es
Background: The purpose of this study was to describe anterior segment changes in a prospective, interventional, noncomparative case series of patients with neovascular glaucoma secondary to proliferative diabetic retinopathy treated with intravitreal bevacizumab.

Methods: Five consecutive patients with neovascular glaucoma and a refractory, symptomatic elevation of intraocular pressure and pronounced anterior segment congestion received intravitreal bevacizumab $1.25 \mathrm{mg} / 0.05 \mathrm{~mL}$. Follow-up examinations were performed at 4-16 weeks by the same specialists, with testing performed at hour 48 , week 1 , and months 1,3 , and 6 after intravitreal bevacizumab.

Results: We observed a significant difference $(P=0.021)$ between initial and mean neovascularization at three months in all the quadrants. At three months, median intraocular pressure was $19 \pm 5.38$ (range 12-26) $\mathrm{mmHg}$. In three of the five cases, diode laser cyclophotocoagulation was required, and in one case a trabeculectomy was performed. One patient showed complete synechial angle closure 48 hours after treatment which required cyclodestructive procedures to normalize intraocular pressure.

Conclusion: Intravitreal bevacizumab achieves complete regression of neovascularization in neovascular glaucoma secondary to proliferative diabetic retinopathy, and this regression is stable when associated with treatment of the underlying disease and should be investigated more thoroughly as an adjunct in the management of neovascular glaucoma.

Keywords: rubeosis, neovascular, glaucoma, bevacizumab, Avastin ${ }^{\circledR}$, intravitreal, angle closure, complications

\section{Introduction}

Neovascular glaucoma is a secondary form of glaucoma, and in $97 \%$ of cases is due to retinal ischemia secondary to diabetic retinopathy or to central retinal vein occlusion. ${ }^{1,2}$ This clinical entity has a poor prognosis and is difficult to treat either medically or surgically, despite numerous efforts in this field.

We are seeing a growing number of case series reporting use of bevacizumab in the treatment of neovascular glaucoma secondary to proliferative diabetic retinopathy or central retinal vein occlusion, where the authors concur that there is a rapid regression of iris neovessels and iridocorneal angle neovascularization after administration of intraocular antiangiogenic agents. ${ }^{3-12}$ Some studies show a reduction of intraocular pressure, resolution of vitreous hemorrhage, and absence of neovascular leakage by iris fluorescein angiography at the end of follow-up. ${ }^{13-16}$ However, there is little information about the possible complications of this form of treatment for neovascular glaucoma. ${ }^{17}$ 
We conducted a prospective study of patients diagnosed with neovascular glaucoma secondary to proliferative diabetic retinopathy in order to describe anterior segment changes after intravitreal bevacizumab administration.

\section{Materials and methods}

We performed a prospective, interventional, noncomparative study of five consecutive patients diagnosed with neovascular glaucoma secondary to proliferative diabetic retinopathy who were treated between March and September 2007. Approval was obtained prior to initiation of this study by the institutional review board of the Barraquer Ophthalmology Centre. Informed consent was signed by all the patients for treatment with intravitreal bevacizumab and inclusion in the study. Bevacizumab was administered in the operating room under topical anesthetic by intravitreal injection of $0.05 \mathrm{~mL}$ $\left(1.25 \mathrm{mg}\right.$ ) of a commercial preparation (Avastin ${ }^{\circledR}$, Genetech Inc, San Francisco, CA).

The primary objective was to evaluate regression of the iris and iridocorneal angle neovessels and angular structural changes, as well as variations in intraocular pressure and visual acuity after one intravitreal dose of bevacizumab $1.25 \mathrm{mg}$ in patients diagnosed with neovascular glaucoma secondary to proliferative diabetic retinopathy. Initially, all patients underwent complete ophthalmologic examination by glaucoma and vitreous-retina specialists, and were then referred to an internist for systemic evaluation and treatment. All patients were followed by the same specialists, with testing performed at hour 48 , week 1 , and months 1, 3, and 6 after intravitreal bevacizumab. Panretinal photocoagulation or peripheral retinal cryocoagulation was performed beginining one week after intravitreal bevacizumab in order not to mask the initial acute effects of intravitreal bevacizumab.

Evolution of neovascularization was monitored by serial iris photography and gonioscopy. Anatomical structures of the iris (margin, stroma, periphery) and the angle were divided into four quadrants; the presence of neovascularization was scored on a scale of 0 to 4 points, according to the number of quadrants affected ( 1 point $=$ one quadrant $)$. The degree of angular amplitude variation was measured by anterior segment optical coherence tomography (Visante ${ }^{\circledR}$, Zeiss Optical Systems) at $0^{\circ}, 90^{\circ}, 180^{\circ}$, and $270^{\circ}$ before and after treatment.

Statistical analysis was performed using the $t$-test and Mann-Whitney $U$ test for continuous variables, and the Chi-square test was used for discrete variables. Only $P$ values $<0.05$ were considered statistically significant.

\section{Results}

Five eyes from five patients (four women and one man) aged $62.5 \pm 6.26$ (53-69) years were treated. Mean follow-up was 20.4 (range 1-32) weeks. At the end of follow-up, four cases showed complete remission of rubeosis and angular neovascularization, with a mean intraocular pressure of $17.8 \pm 5.38 \mathrm{mmHg}$. We did not observe any secondary systemic effects.

Initial visual acuity varied from light perception to 20/50; two eyes remained stable, two deteriorated, and one case showed improved visual acuity after treatment. In all cases, retinal photocoagulation was completed within the first month after intravitreal bevacizumab. In one case, pars plana vitrectomy was performed due to massive vitreous hemorrhage.

Initial median intraocular pressure was $23 \pm 11.32$ (range 17-45) $\mathrm{mmHg}$ under maximum topical and systemic medication, increasing to $50 \mathrm{mmHg}$ at 48 hours. At three months, median intraocular pressure was $19 \pm 5.38$ (12-26) mmHg. In three of the five cases, diode laser cyclophotocoagulation was required, and in one case a trabeculectomy was performed. Only one case remained normotensive with no more than topical treatment.

We observed a significant $(P=0.021)$ difference between initial and mean neovascularization at three months in all the quadrants. In three cases, remission was complete at 48 hours; in four eyes, this was complete and stable until the third month, and one eye showed neovascular relapse in one of the quadrants. In all cases, the most affected anatomical structure was the iris margin. Intraocular pressure and neovascularization evolution are shown in Tables 1 and 2 . The degree of angular goniosynechia at baseline was $360^{\circ}$ in two of patients, none in two patients, and $180^{\circ}$ in one patient. No patient showed any increase in angular goniosynechia after treatment.

In two cases, we detected a slight decrease in anterior chamber amplitude and a global reduction of the iridocorneal angle with incomplete angle closure. One patient (case 5) showed complete synechial angle closure 48 hours after treatment which required cyclodestructive procedures to normalize intraocular pressure, and is described here.

\section{Case report}

Patient 5 was a 61 -year-old man with a 20 -year history of poorly controlled diabetes mellitus presented with proliferative diabetic retinopathy previously treated with partial peripheral panretinal photocoagulation and cryocoagulation. He had neovascular glaucoma with rubeosis in the entire iris and 
Table I Intravitreal bevacizumab in the treatment of neovascular glaucoma due to proliferative diabetic retinopathy: Review of a series of five cases

\begin{tabular}{|c|c|c|c|c|c|c|c|c|c|c|}
\hline \multirow[t]{2}{*}{ Case } & \multirow{2}{*}{$\begin{array}{l}\text { Age } \\
\text { (years) }\end{array}$} & \multirow[t]{2}{*}{ Gender } & \multicolumn{3}{|l|}{ IOP } & \multirow{2}{*}{$\begin{array}{l}\text { Glaucoma } \\
\text { Procedure }\end{array}$} & \multicolumn{2}{|l|}{ BCVA } & \multirow{2}{*}{$\begin{array}{l}\text { DRP } \\
\text { treatment }\end{array}$} & \multirow{2}{*}{$\begin{array}{l}\text { Follow-up } \\
\text { (weeks) }\end{array}$} \\
\hline & & & Pre IVB & 48 hours & End & & Pre IVB & End & & \\
\hline I & 64 & $\mathrm{~F}$ & 19 & 20 & 16 & Trabeculectomy & 0.45 & 0.2 & $P P V+P C G$ & 20 \\
\hline 2 & 69 & $\mathrm{~F}$ & 45 & 56 & 26 & Cyclophotocoagulation & $\mathrm{HM}$ & $\mathrm{HM}$ & None & 15 \\
\hline 3 & 67 & $\mathrm{~F}$ & 17 & 16 & 17 & None & 0.3 & 0.4 & $P C G+C C G$ & 20 \\
\hline 4 & 53 & $\mathrm{~F}$ & 30 & 60 & 12 & Cyclophotocoagulation & $\mathrm{HM}$ & HM & PCG & 15 \\
\hline 5 & 61 & $M$ & 23 & 50 & 14 & Cyclophotocoagulation & 0.3 & 0.25 & PCG & 32 \\
\hline
\end{tabular}

Abbreviations: IOP, intraocular pressure; IVB, intravitreal bevacizumab; BCVA, best corrected visual acuity; DRP, diabetic retinopathy; F, female; M, male; HM, hand motion; PPV, pars plana vitrectomy; PCG, photocoagulation; CCG, cryocoagulation.

angle, with an intraocular pressure of $23 \mathrm{mmHg}$ on maximum topical and systemic therapy. At 48 hours after intravitreal bevacizumab, we observed a decrease in anterior chamber amplitude as well as complete synechial angle closure (see Figures 1 and 2), and his intraocular pressure had increased to $50 \mathrm{mmHg}$. Diode laser cycloablation of the ciliary body was performed.

\section{Discussion}

Intravitreal bevacizumab is now a frequently used drug for the combined treatment of neovascular glaucoma. ${ }^{6-11,18}$ In our study, three of five cases required diode laser cyclophotocoagulation in the first three to five days following intravitreal bevacizumab to control intraocular pressure elevations which were refractory to any medical treatment. Rubeosis diminished in the first 48 hours after intravitreal bevacizumab, possibly due to nonperfusion of the neovessels rather than complete disappearance, because some of the serial photographs clearly showed the re-emergence of the neovessels. The angle was the anatomical structure most severely affected, but also showed the most rapid regression. Complete resolution of rubeosis occurred in four cases, which supports the idea that bevacizumab could be used to decrease the vascular endothelial growth factor concentration and to induce regression of rubeosis and neovascularization of the iridocorneal angle.
Overall, the results are similar to those of other published series regarding immediate neovascular regression after intravitreal bevacizumab, with an initial increase and subsequent short-term reduction of intraocular pressure. ${ }^{3-8,10-14,16}$ However, only one paper reports acute angle closure glaucoma as a complication of intravitreal injection of bevacizumab. ${ }^{17}$ We consider this point especially interesting, because this was observed in three of five cases in our series. We suggest that bevacizumab-induced neovascular collapse induces fibrovascular contraction and anterior displacement of the iris-body ciliary-zonular complex. This structural alteration reduces anterior chamber and iridocorneal amplitude, with a possible decompensation of intraocular pressure due to loss of the angular structures. In our experience, anterior segment optical coherence tomography is a valuable tool for monitoring the angle status.

Although intraocular pressure after intravitreal bevacizumab remained unchanged in two cases, the other three showed marked increases at the first follow-up visit at 48 hours. This decompensation could be related to a decrease in angular amplitude, observed by anterior segment optical coherence tomography, although prospective randomized studies with larger sample sizes would be necessary to confirm a possible relationship between regressed neovascularization and angle contraction due to the treatment.

Table 2 Intravitreal bevacizumab in the treatment of neovascular glaucoma due to proliferative diabetic retinopathy: Variations in neovascularization according to angle and anterior chamber

\begin{tabular}{|c|c|c|c|c|c|c|c|c|c|c|c|c|c|c|}
\hline \multirow[t]{3}{*}{ Case } & \multicolumn{12}{|c|}{ Neovascularization by quadrants } & \multicolumn{2}{|c|}{ Variation after IVB } \\
\hline & \multicolumn{4}{|c|}{ Pre IVB } & \multicolumn{4}{|c|}{48 hours post IVB } & \multicolumn{4}{|c|}{ End follow-up } & \multirow[t]{2}{*}{ Angle } & \multirow[t]{2}{*}{ Anterior chamber } \\
\hline & $\mathbf{M}$ & $\mathbf{S}$ & $\mathbf{P}$ & $\mathbf{A}$ & $\mathbf{M}$ & $\mathbf{S}$ & $\mathbf{P}$ & $\mathbf{A}$ & $\mathbf{M}$ & $\mathbf{S}$ & $\mathbf{P}$ & $\mathbf{A}$ & & \\
\hline I & $4 / 4$ & - & - & - & - & - & - & - & - & - & - & - & Decreased & Stable \\
\hline 2 & $2 / 4$ & $2 / 4$ & - & $2 / 4$ & - & - & - & - & - & - & - & - & Decreased & Decreased \\
\hline 3 & $4 / 4$ & - & - & $2 / 4$ & - & - & - & - & - & - & - & - & Stable & Stable \\
\hline 4 & $4 / 4$ & - & - & - & - & - & - & - & - & - & - & - & Stable & Stable \\
\hline 5 & $4 / 4$ & $2 / 4$ & $2 / 4$ & $2 / 4$ & - & - & $1 / 4$ & $1 / 4$ & $1 / 4$ & - & - & - & Decreased & Decreased \\
\hline
\end{tabular}

Abbreviations: IVB, intravitreal bevacizumab; $M$, iris margin; $S$, iris stroma; $P$, iris periphery; $A$, angle. 

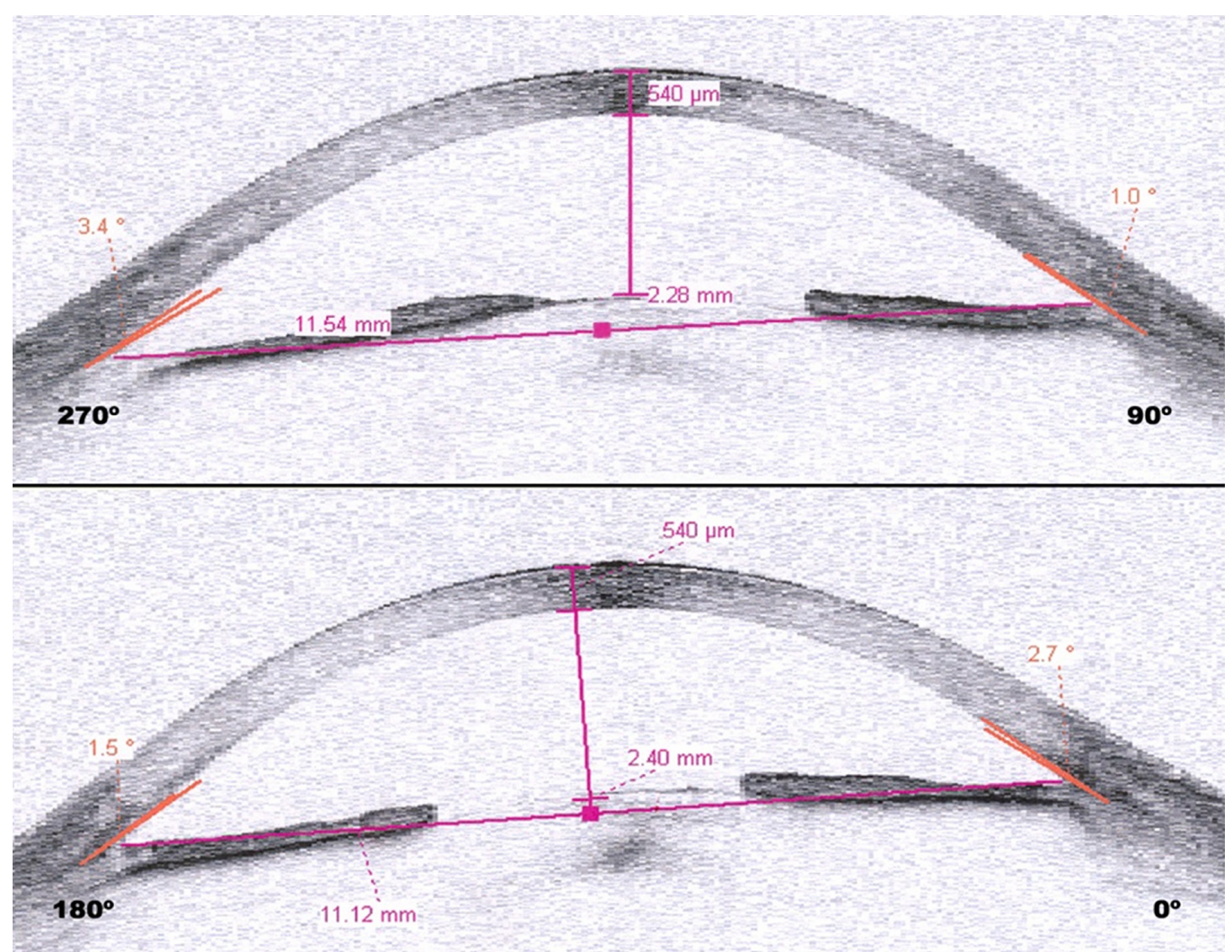

Figure I Case 5. Anterior chamber image obtained by anterior segment optical coherence tomography prior to treatment. Notice the narrow but open angle.

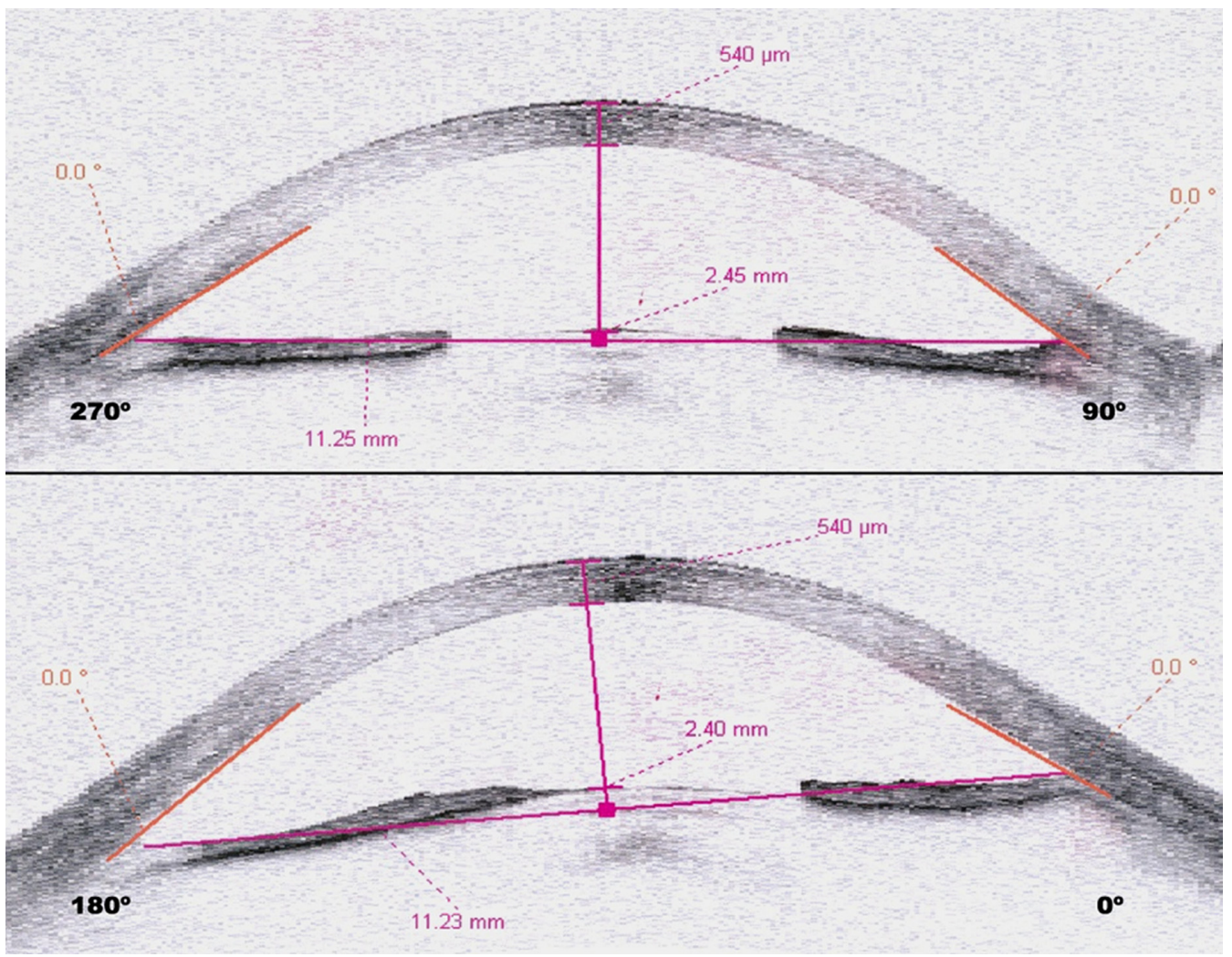

Figure 2 Case 5. Anterior segment optical coherence tomography obtained 48 hours following treatment showing complete angular closure. 
Intraocular pressure values at the end of follow-up were clearly modified by surgical procedures aimed at maintaining these values within normal limits. The reduction observed at the end of follow-up can not only be related to treatment with intravitreal bevacizumab, but also to a combination of this treatment and the surgical procedures used..$^{8,19-21}$ Intravitreal bevacizumab could improve visual outcomes and decrease the need for glaucoma surgery. ${ }^{22}$ Regression of neovascularization in four of our cases was noted throughout the three months of follow-up, probably due to treatment for diabetic retinopathy being performed in the first month after intravitreal bevacizumab.

It may be concluded that intravitreal bevacizumab achieves a significant regression of neovascularization in neovascular glaucoma secondary to proliferative diabetic retinopathy, and this regression is stable when associated with treatment of the underlying disease. In some cases, we observed increased intraocular pressure with a poor response to topical and/or systemic treatment, associated with reduction of the anterior chamber and the iridocorneal angle. Therefore, we recommend performing a complete evaluation of the extent of neovascularization and degree of angular goniosynechia in order to reduce the possibility of inducing complete angular closure prior to bevacizumab administration, and careful monitoring of the intraocular pressure in the first 48 hours following treatment is needed. We also believe that the maximum degree of neovascularization allowing the completely safe use of bevacizumab remains to be determined.

\section{Disclosure}

The authors report no conflicts of interest in this work.

\section{References}

1. Brown GC, Magargal LE, Schachat, et al. Neovascular glaucoma. Etiologic considerations. Ophthalmology. 1984;91(4):315-320.

2. Allingham RA, Damji KF, Freedman S, et al, editors. Glaucomas associated with disorders of the retina, vitreous and choroids. Shields' Textbook of Glaucoma. 5th ed. Philadelphia, PA: Lippincott, Williams, and Wilkins; 2005.

3. Iliev ME, Domig D, Wolf-Schnurrbursch U, Wolf S, Sarra GM. Intravitreal bevacizumab $\left(\right.$ Avastin $\left.^{\circledR}\right)$ in the treatment of neovascular glaucoma. Am J Ophthalmol. 2006;142(6):1054-1056.

4. Mason JO 3rd, Albert MA Jr, Mays A, Vail R. Regression of neovascular iris vessels by intravitreal injection of bevacizumab. Retina. 2006; 26(7):839-841.

Clinical Ophthalmology

\section{Publish your work in this journal}

Clinical Ophthalmology is an international, peer-reviewed journal covering all subspecialties within ophthalmology. Key topics include: Optometry; Visual science; Pharmacology and drug therapy in eye diseases; Basic Sciences; Primary and Secondary eye care; Patient Safety and Quality of Care Improvements. This journal is indexed on Submit your manuscript here: http://www.dovepress.com/clinical-ophthalmology-journal
5. Silva Paula J, Jorge R, Alves Costa R, Rodrigues Mde L, Scott IU. Short-term results of intravitreal bevacizumab $\left(\right.$ Avastin $\left.^{\circledR}\right)$ on anterior segment neovascularization in neovascular glaucoma. Acta Ophthalmol Scand. 2006;84(4):556-557.

6. Ghanem AA, El-Kannishy AM, El-Wehidy AS, et al. Intravitreal bevacizumab (Avastin) as an adjuvant treatment in cases of neovascular glaucoma. Middle East Afr J Ophthalmol. 2009;16(2):75-79.

7. Douat J, Auriol S, Mahieu-Durringer L, et al. Intravitreal bevacizumab for treatment of neovascular glaucoma. Report of 20 cases. $J \mathrm{Fr}$ Ophtalmol. 2009;32(9):652-663. French.

8. Ciftci S, Sakalar YB, Unlu K, et al. Intravitreal bevacizumab combined with panretinal photocoagulation in the treatment of open angle neovascular glaucoma. Eur J Ophthalmol. 2009;19(6):1028-1033.

9. Yazdani S, Hendi K, Pakravan M, et al. Intravitreal bevacizumab for neovascular glaucoma: A randomized controlled trial. J Glaucoma. 2009; 18(8):632-637.

10. Hasanreisoglu M, Weinberger D, Mimouni K, et al. Intravitreal bevacizumab as an adjunct treatment for neovascular glaucoma. Eur J Ophthalmol. 2009;19(4):607-612.

11. Duch S, Buchacra O, Milla E, et al. Intracameral bevacizumab (Avastin) for neovascular glaucoma: A pilot study in 6 patients. J Glaucoma. 2009; 18(2):140-143.

12. Wakabayashi T, Oshima Y, Sakaguchi H, et al. Intravitreal bevacizumab to treat iris neovascularization and neovascular glaucoma secondary to ischemic retinal diseases in 41 consecutive cases. Ophthalmology. 2008;115(9):1571-1580.

13. Davidorf FH, Mouser JG, Derick RJ. Rapid improvement of rubeosis iridis from a single bevacizumab $\left(\right.$ Avastin $\left.^{\circledR}\right)$ injection. Retina. 2006; 26(3):354-356.

14. Grisanti S, Biester S, Peters S, Tatar O, Ziemssen F, Bartz-Schmidt KU; Tuebingen Bevacizumab Study Group. Intracameral bevacizumab for iris rubeosis. Am J Ophthalmol. 2006;142(1):158-160.

15. Kahook MY, Schuman JS, Noecker RJ. Intravitreal bevacizumab in a patient with neovascular glaucoma. Ophthalmic Surg Lasers Imaging. 2006;37(2):144-146.

16. Sugimoto Y, Mochizuki H, Okumichi H, et al. Effect of intravitreal bevacizumab on iris vessels in neovascular glaucoma patients. Graefes Arch Clin Exp Ophthalmol. 2010;248(11):1601-1609.

17. Semoun O, Blumen-Ohana E, de Preobrajensky N, et al. Acute angleclosure glaucoma complicating an intravitreal injection of bevacizumab. J Fr Ophtalmol. 2009;32(1):58.e1-4. French.

18. Moraczewski AL, Lee RK, Palmberg PF, et al. Outcomes of treatment of neovascular glaucoma with intravitreal bevacizumab. Br J Ophthalmol. 2009;93(5):589-593.

19. Alkawas AA, Shahien EA, Hussein AM. Management of neovascular glaucoma with panretinal photocoagulation, intravitreal bevacizumab, and subsequent trabeculectomy with mitomycin C. J Glaucoma. 2010; 19(9):622-626.

20. Saito $Y$, Higashide T, Takeda $H$, et al. Clinical factors related to recurrence of anterior segment neovascularization after treatment including intravitreal bevacizumab. Am J Ophthalmol. 2010;149(6): 964-972.e1.

21. Vasudev D, Blair MP, Galasso J, et al. Intravitreal bevacizumab for neovascular glaucoma. J Ocul Pharmacol Ther. 2009;25(5):453-458.

22. Lupinacci AP, Calzada JI, Rafieetery M, et al. Clinical outcomes of patients with anterior segment neovascularization treated with or without intraocular bevacizumab. Adv Ther. 2009;26(2):208-216.

\section{Dovepress}

PubMed Central and CAS, and is the official journal of The Society of Clinical Ophthalmology (SCO). The manuscript management system is completely online and includes a very quick and fair peer-review system, which is all easy to use. Visit http://www.dovepress.com/ testimonials.php to read real quotes from published authors. 